University of Nebraska - Lincoln

DigitalCommons@University of Nebraska - Lincoln

Entomology Papers from Other Sources

Entomology Collections, Miscellaneous

1988

Do Ant Brood Pheromones Exist?

Laurence Morel

USDA-ARS

Robert K. Vander Meer

USDA-ARS

Follow this and additional works at: https://digitalcommons.unl.edu/entomologyother

Part of the Entomology Commons

Morel, Laurence and Vander Meer, Robert K., "Do Ant Brood Pheromones Exist?" (1988). Entomology

Papers from Other Sources. 54.

https://digitalcommons.unl.edu/entomologyother/54

This Article is brought to you for free and open access by the Entomology Collections, Miscellaneous at DigitalCommons@University of Nebraska - Lincoln. It has been accepted for inclusion in Entomology Papers from Other Sources by an authorized administrator of DigitalCommons@University of Nebraska - Lincoln. 


\title{
Do Ant Brood Pheromones Exist?
}

\author{
LAURENCE MOREL AND ROBERT K. VANDER MEER \\ Insects Affecting Man and Animals Laboratory, USDA-ARS, \\ Gainesville, Florida 32604
}

\begin{abstract}
FORUM: Ann. Entomol. Soc. Am. 81(5): 705-710 (1988)
ABSTRACT A brood pheromone is a chemical or mixture of chemicals released by immature stages that elicits a behavioral response in conspecific adults. The current literature devoted to brood pheromones in several ant species does not prove the existence of such a pheromone or even of brood-specific chemicals. The possibility of a food response or a nestmate recognition response, two of the most confounding factors, has not been eliminated. Two alternative hypotheses involving brood behavior, morphology, cuticular chemicals, and associative learning are proposed.
\end{abstract}

KEY WORDS Insecta, ant, brood, pheromones

THE DIFFERENTIAL TREATMENT received by brood (immature stages) in ants (Le Masne 1953), and experimental evidence that workers of Neivamyrmex opacithorax (Emery) show an aggregation response to larval secretions (Watkins \& Cole 1966), led to the hypothesis that ant brood produces pheromones that elicit specific adult behaviors. From the early 1970s to the present, several studies have attempted to document the existence of brood pheromones; most effort has been directed toward the fire ant, Solenopsis invicta Buren (Vander Meer 1983).

Several problems arise in demonstrating conclusively that brood does produce pheromones. Most important are the species-specificity of a pheromone, the adequacy of bioassays, the existence of reliable controls (which include food and nestmate recognition controls), the quantity of material used to obtain a positive response, and chemical techniques. Here we review how these different problems have been addressed in the current literature and whether or not they have been solved. We then review the experimental support for the involvement of nonchemical cues in the differential treatment of ant brood and propose some alternative hypotheses.

\section{Brood Pheromone Classifications}

Brood pheromones can be classified in several categories according to the behavioral reactions they elicit.

Brood Recognition: Suggests that the surface chemistry of brood is recognized by adult ants as being different from that of adults. At a more refined level, each immature developmental stage may produce a specific pheromone that is distinguished by adult workers, leading to segregation of immature stages in the nest (see Le Masne 1953).
Attraction: Suggests that brood releases a volatile pheromone that attracts adults.

Aggregation: Involves clustering of ants on or around a substance secreted by brood that elicits settling behavior in workers.

Brood-Tending: An all-encompassing term for several adult behaviors toward brood, which include feeding, grooming, and (under disrupted colony conditions) retrieval back to the nest. The only tending behavior used in brood pheromone bioassays to date has been retrieval to the nest. Brood recognition is prerequisite to these worker responses.

\section{Problems in Demonstrating Brood Pheromones}

Species-Specificity. The term "pheromone" is defined as a substance released by an organism to the outside that causes a specific behavioral or physiological reaction in a receiving organism of the same species (Nordlund \& Lewis 1976). The specificity of pheromones contributes to the isolation of sympatric species (Roelofs 1981). There are also examples of species with common pheromone components; however, it is not clear that the total blend of chemicals used by a species to attain the full behavioral repertoire is matched by any other species. In particular, it is unlikely that pheromones responsible for the full range of ant worker behaviors associated with rearing brood would be identical among several species. The chemical isolation and identification of pheromone components are limited by the bioassay, which usually breaks down a complex sequence of behaviors into a single measurable response. This limitation was illustrated by studies on trail pheromones in two species of fire ants. A trail-following (i.e., orientation) bioassay demonstrated the lack of species-specific- 
ity in Solenopsis richteri Forel and S. invicta (Barlin et al. 1976). However, subsequent research showed that species-specificity was achieved during recruitment, another element of the trail pheromone behavioral hierarchy (Vander Meer 1986, Vander Meer et al. 1988).

The problem of species-specificity has not been addressed in brood pheromone studies, although Brian (1975) suggested a chemical is released by queen-biased larvae of Myrmica rubra L. that elicits a worker response (aggression, leading to the loss of queen potentiality); this effect was transspecific between $M$. rubra and $M$. scabrinodis $\mathrm{Ny}$ lander. The conceptual problem of the speciesspecificity of brood pheromones is important, because interspecific adoption of brood is widely reported (see Jaisson 1971). In addition, the demonstration of brood pheromone species-specificity would help to eliminate the confounding food response factor.

Adequacy of Bioassays. The adequacy of a bioassay to test an hypothesis becomes acute when the test objects are not live animals. A widely used bioassay consists of retrieval of inert objects treated with brood extracts (Glancey et al. 1970, Robinson \& Cherrett 1974, Walsh \& Tschinkel 1974, Bigley \& Vinson 1975, Brian 1975, LaMon \& Topoff 1985, Glancey \& Dickens 1988). However, this bioassay can be confounded by food responses as discussed below. To overcome this problem, some experimenters (Walsh \& Tschinkel 1974, Brian 1975, LaMon \& Topoff 1985) used a nest design that incorporated a distinct brood chamber. Retrieval of tested objects into the brood chamber was used as the criterion for a brood-specific worker response. However, because food must be brought to the larvae by workers, a food response cannot be eliminated.

In some cases, bioassays designed to demonstrate the existence of attractant brood pheromones (Watkins \& Cole 1966, Glancey \& Dickens 1988) actually measured aggregation. In these bioassays, the cumulative number of ants was counted at various times at a spot of test material. The difficulty with this kind of test is that during random searching, worker ants could contact the spot and aggregate. Therefore, it is not possible to associate attraction with the test results. The only way to measure attraction is via an olfactometer which, by definition, measures only the response to volatiles. Walsh \& Tschinkel (1974) used this technique to determine if fire ant brood produces a volatile attractant. They allowed only one ant to make a choice before cleaning the apparatus, thus preventing subsequent workers from following the first ant's trail. Walsh \& Tschinkel (1974) concluded that fire ant brood does not produce a volatile pheromone. Vander Meer et al. (1988) designed a Y-tube olfactometer that measured the initial choice of the first 20 ants. Because fire ant trail-laying occurs on the return to the nest (Wilson 1962), it was assumed that trail formation was not a complicating factor. Glancey
\& Dickens (1988) subsequently used this type of olfactometer to bioassay volatiles from larvae. They found that at least 30 live immatures were required to elicit a significant response. LaMon \& Topoff (1985) studied the involvement of pheromones in social facilitation of eclosion in S. invicta. Workers are attracted to eclosing pupae and then avidly strip away the pupal skin. However, LaMon \& Topoff's bioassays measure only aggregation and retrieval, which appear to be inappropriate to quantify attraction. A more appropriate bioassay may be to apply rinses of eclosing pupae to noneclosing pupae and monitor worker behavior.

Reliability of Controls. In each study, the reliability of controls used to differentiate food or nestmate recognition responses from brood pheromone responses is questionable. Several investigators have attempted to deal with the food response problem by requiring (for a positive result) that brood-treated particles be deposited in a brood chamber, or comparing response to the test sample with that to food controls. However, with the first method, workers feed the larvae and therefore must bring food into the brood chamber. The type of food used as a control also presents problems. For example, the food value of a soybean oil control (Glancey et al. 1970, Bigley \& Vinson 1975) is not similar to the food value of extracted brood. Extracted brood contains a complex mixture of lipids, proteins, carbohydrates, etc., whereas soybean oil contains mostly triglycerides. The cockroach rinse used as a food control by Glancey \& Dickens (1988) is not fully satisfactory either, because the weights of extracted material from cockroaches and brood were not matched, and the relative amounts of lipid classes were not investigated in the two extracts. Walsh \& Tschinkel (1974) dampened out the food response by overfeeding the colony with the food used as a control. However, as demonstrated by these authors, such dampening may only increase the probability of workers responding to a novel food source (i.e., brood extract). Ideally, one should use a food control that consists of an equivalent amount of extract, by weight, of a non-ant larval form not currently in the colony diet.

Glancey \& Dickens (1988) used an electroantennogram (EAG) assay to test for a volatile component of the fire ant's brood pheromone. The mean EAG response to their control (hexanol, $100 \mu \mathrm{g}$ ) was small $(-0.38 \mathrm{mV})$, and the response to brood (100 larva-equivalent) was much smaller $(-0.01$ $\mathrm{mV}$ ). The authors argued that the low response to brood is significant because the ants may have numerous receptors to hexanol (green leaf volatile) but only a few highly specific brood pheromone receptors. This is not a convincing argument, for Vander Meer (unpublished data) obtained a -0.5 $\mathrm{mV}$ EAG response from fire ant workers to 0.2 queen equivalents of the queen attractant pheromone. For the EAG test of the brood volatile, it would have been better to have used a solvent control and to have tested a known fire ant pher- 
omone standard (e.g., queen attractant pheromone [Glancey 1986]) in sequence with unknowns.

None of the brood pheromone studies used worker or sexual adult ants as controls, either intact or as extracts. Therefore, it is impossible to determine if the behaviors elicited were general nestmate or species-specific responses obtainable from any colony group. Walsh \& Tschinkel (1974) used adult male body contents as a colony response control; however, this does not take into account that colony discrimination cues are probably located on the cuticle (Wilson 1971). Moreover, colony discrimination occurs principally among workers and may be applied in a different way, or not at all, to adult sexuals. Ant brood appears to be colony-specific to a certain extent in Lasius niger L. (Lenoir 1981) and in Cataglyphis cursor Fonscolombe (Lenoir 1984, Isingrini et al. 1985). Although initially there is a differential treatment of alien brood, intercolony adoption in these two species has always been successful. In $S$. invicta, no significant differences have been found between the worker response to nestmates and to alien brood (Glancey \& Dickens 1988). Results may vary among species, but at this point we cannot eliminate colony recognition as an explanation of the results obtained in brood pheromone bioassays

Quantitation. The wealth of pheromone research on ants and other insects has shown that pheromones are present in minute quantities relative to the individual's biomass. For example, each fire ant queen has only about $10 \mathrm{ng}$ of attractant pheromone (Glancey 1986), and the trail orientation and recruitment pheromones occur at only 6 and $0.075 \mathrm{ng}$ per worker, respectively (Vander Meer et al. 1981, Vander Meer et al. 1988). Behavioral responses to these fire ant pheromones are obtained with one or fewer body-equivalents. Consequently, serious questions arise when investigations of a brood pheromone require whole-body extracts or a large number of brood or both to elicit worker responses (Glancey et al. 1970, Bigley \& Vinson 1975, Glancey \& Dickens 1988). The last-named authors showed that 500 larva equivalents were required for a positive worker response in a "spot" bioassay (aggregation), and 300 living larvae were required for a positive response in an olfactometer. The need for so many immatures suggests that the results of the rinse may be a response to food or contamination from pheromone released by nestmates (e.g., trail and queen pheromones). The olfactometer results could be caused by the asymmetry of the air streams created by the respiratory products of the large amount of brood used in the experiment. These results represent an effect of the group (which may, in fact, be real in a colony situation where immature stages are concentrated). However, in retrieval experiments, workers do respond to individual living immatures (i.e., in a disrupted colony).

One of the most frustrating inadequacies in many brood pheromone papers (Watkins \& Cole 1966,
Glancey et al. 1970, Bigley \& Vinson 1975, LaMon \& Topoff 1985) is the lack of information regarding the brood equivalents of the extracts and amount of the control substances used in bioassays. Without this information, it is impossible to determine if a pheromonal response is being tested. Glancey et al. (1970) and Bigley \& Vinson (1975) used extracts of crushed immatures; yet discrimination cues such as a brood recognition pheromone are most likely to be found on the cuticular surface rather than within the body (Wilson 1971). Moreover, the use of whole-body extracts increases the food value of the test material, which may swamp out potential pheromonal responses.

Chemical Techniques. Bigley \& Vinson (1975) used inappropriate chemical techniques to mistakenly identify triolein as the brood pheromone in $S$. invicta (see Vander Meer [1983] and Vander Meer \& Morel [1988] for details).

\section{Evidence for Involvement of Nonchemical Signals in Specific Behaviors Directed to Brood}

Morphology. Immature stages obviously differ morphologically from adults. Also, differences exist between the various brood stages (egg, larva, pupa) and even between the successive larval stages, as reported for S. invicta (Petralia \& Vinson 1979). Morphological properties of third instars and pharate pupae of $M$. rubra were investigated for possible recognition cues by Brian (1975). In this case, flaccidity and hairiness play a significant role in eliciting retrieval to the brood chamber. Robinson \& Cherrett (1974) concluded that the diminished retrieval of freeze-killed Atta cephalotes L. larvae was caused by a deterioration of their physical properties.

Behavior. Brood behavior is very different from adult behavior; however, it has not been investigated as a possible cue inducing brood-directed behavior. The most obvious larval behavior is the exchange of liquids with workers (trophallaxis); this exchange is bidirectional and both individuals benefit (Wilson 1971). Although pupae lack noticeable behavior, investigators can recognize eclosing pupae by their gross uncoordinated movements (e.g., LaMon \& Topoff 1985). Worker ants may respond to eclosing pupae using these cues.

\section{Alternative Hypotheses}

Adult ants distinguish brood from adults and different brood stages from each other. Some studies suggest that chemical signals mediate these distinct behaviors; e.g., loss of activity following solvent rinses (Robinson \& Cherrett 1974, Brian 1975). However, none of the studies we reviewed demonstrated the unambiguous existence of a brood pheromone in the strictest sense. If brood pheromones do exist, technical difficulties in the devel- 
opment of bioassays or chemical methodologies so far have precluded their clear demonstration. However, in our opinion, the current literature more strongly supports the possibility that brood pheromones do not exist in ants.

From the literature about adult/brood interactions in ants, we can conclude that an "I am brood" signal is not located on a specific part of the body of the immature form (Walsh \& Tschinkel 1974, Brian 1975); body morphology can be a cue used by adults to distinguish brood from adults (Robinson \& Cherrett 1974, Brian 1975); interspecific adoptions of brood between related species have been known for a long time (see Jaisson 1971) and workers in the host colony display typical broodtending behaviors toward the adoptees; and that interspecific adoptions are also successful with newly eclosed (callow) workers (see Jaisson 1971).

It is possible, then, that adult behavior toward brood can be moderated by a combination of morphological, behavioral, and cuticular chemical factors. We propose two alternative hypotheses that involve these factors to explain the differential treatment of brood by adult ants.

Under the first hypothesis, we define the brood cuticular chemicals involved in worker-brood interactions as nestmate recognition cues. These cues can be derived from any source-the individual itself, nestmates, or the environment. In addition, these cues elicit different behaviors (acceptance or rejection) in individuals of the same species under the same experimental conditions. For these reasons, they should not be considered pheromones (Vander Meer 1988). The cues, whatever their source, are transferred between workers (Errard \& Jallon 1987; Vander Meer \& Carlin, unpublished data) and are probably also transferred to brood. As shown in two species, Lasius niger L. (Lenoir 1981) and C. cursor (Lenoir 1984, Isingrini et al. 1985), there is colony-brood recognition. However, colony discrimination of alien brood lasts only a short time, and foreign brood is soon fully adopted. These data suggest that time is required for the brood to acquire the host colony's odor (nestmate recognition cues). Initially, alien brood of these two species receive quantitatively less care than nestmate brood. Therefore, nestmate recognition cues may be involved in quantitative differences in the specific treatment of brood, whereas other cues (morphology and behavior) may be responsible for the specific treatment itself. The combination of chemical recognition with morphological or behavioral cues or both could in fact be sufficient to account for the full differential treatment of brood by adult ants. Brood-derived nestmate recognition cues could account for all results obtained with bioassays in which brood rinses or extracts are tested as baits (although results with brood extracts are most likely food responses). The contribution of each factor (morphology, behavior, nestmate recognition cues) may vary from species to species. As shown in the brood pheromone literature, modi- fication of any of the factors may affect the behavior of workers toward brood.

The second hypothesis is an expansion of the first based on associative learning of a characteristic (morphological, behavioral, or chemical) of brood and a "reward" obtained by adult workers from brood. Learning in ants and other social insects has been known for a long time (Alloway 1972, Menzel 1985). The concept of rewards moderating ant behavior is well documented in studies on ants tending aphids (Way 1963), Lepidoptera larvae (Cottrell 1984, Maschwitz et al. 1986) and in trophallactic appeasement among ants (Kloft 1983). If chemicals alone were used as the identifying character, they would have to be specific to the brood. The worker reward for tending brood may be related to the observed ingestion of oral secretions and excretory products from larvae (see Le Masne 1953). These products may have nutritive value for recipient workers (Wilson 1971). Queens of mature colonies of the primitive ant Amblyopone silvestrii Wheeler feed entirely on the hemolymph of their own larvae in nondestructive cannibalism (Masuko 1986). In addition, fourth-instar regurgitates of $S$. invicta play an important role in colony nutrition and, in particular, queen egg production (Tschinkel in press). This learning hypothesis can account directly for the behavior of workers toward larvae and possibly eclosing pupae. Although eggs and pupae do not offer workers a reward, the benefits of the associative learning could be extended to all stages.

The combination of multiple signals in brood recognition has been demonstrated in honey bees and Vespa wasps. Although chemical signals from the brood have been found, mechanical and morphological cues are also necessary to induce tending in these social insects (Free \& Winder 1983, Koeniger 1984). Invoking multiple factors in ant broodworker interactions, based on either of the above hypotheses, offers an interesting explanation for the successful adoption of brood into alien colonies. Aggressive behavior between two workers of two colonies of the same species, or two different species, involves recognition and a hierarchy of agonistic behaviors in both partners. Because brood lack the ability for agonistic display, it would be predicted that aggressive behavior toward them would be moderated even if their nestmate recognition label did not match that of the receiving colony (see Breed \& Bennett [1987] for a review of nestmate recognition). Once inside the foreign colony, the successful adoptee can begin to acquire a new colony odor through social interactions. This situation may be analogous to the passive integration mechanism used by a myrmecophilous beetle (Vander Meer \& Wojcik 1982). The limitation of interspecific adoption of brood to closely related species (Jaisson 1971) indicates that species differences in one or some combination of the three factors (most likely morphology or cuticular chemistry or both) negatively influences interspecific brood-worker 
interactions. Similarly, the acceptance of callow workers in alien colonies may be attributed to their reduced behavioral repertoire and lack of acquired nestmate recognition cues, as cited by Jaisson (1985).

The hypotheses presented here are testable and require supporting experimental evidence. We hope this critical review of brood pheromone literature and the alternative propositions stimulate interest and research in this extremely complicated but fascinating area.

\section{Acknowledgment}

We thank C. S. Lofgren, N. Carlin, J. Sivinski, and M. Stowe for reviewing the manuscript.

\section{References Cited}

Alloway, T. M. 1972. Learning and memory in insects. Annu. Rev. Entomol. 17: 43-56.

Barlin, M. R., M. S. Blum \& J. M. Brand. 1976. Fire ant trail pheromones: analysis of species specificity after gas chromatographic fractionation. J. Insect Physiol. 22: 839-844.

Bigley, W. S. \& S. B. Vinson. 1975. Characterization of a brood pheromone isolated from the sexual brood of the fire ant, Solenopsis invicta. Ann. Entomol. Soc. Am. 68: 301-304.

Breed, M. D. \& B. Bennett. 1987. Kin recognition in highly eusocial insects, pp. 243-286. In D. J. C. Fletcher \& C. D. Michener [eds.], Kin recognition in animals. Wiley, New York.

Brian, M. V. 1975. Larval recognition by workers of the ant Myrmica. Anim. Behav. 23: 745-756.

Cottrell, C. B. 1984. Aphytrophagy in butterflies: its relationship to myrmecophily. Zool. J. Linn. Soc. 79: $1-57$

Errard, C. \& J. M. Jallon. 1987. An investigation of the development of chemical factors in ants intrasociety recognition, p. 478. In J. Eder \& H. Rembold [eds.], Chemistry and biology of social insects. Verlag J. Peperny, München.

Free, J. B. \& M. E. Winder. 1983. Brood recognition by honeybee (Apis mellifera) workers. Anim. Behav. 31: 539-545.

Glancey, B. M. 1986. The queen recognition pheromone of Solenopsis invicta, pp. 223-230. In C. S. Lofgren \& R. K. Vander Meer [eds.], Fire ants and leaf-cutting ants: biology and management. Westview, Boulder, Colo.

Glancey, B. M. \& J. C. Dickens. 1988. Behavioral and electrophysiological studies with live larvae and larval rinses of the red imported fire ant, Solenopsis invicta Buren (Hymenoptera: Formicidae). J. Chem. Ecol. 14: 463-473.

Glancey, B. M., C. E. Stringer, C. H. Craig, P. M. Bishop \& B. B. Martin. 1970. Pheromone may induce brood tending in the fire ant, Solenopsis saevissima. Nature 226: 863-864.

Isingrini, M., A. Lenoir \& P. Jaisson. 1985. Preimaginal learning as a basis of colony-brood recognition in the ant Cataglyphis cursor. Proc. Nat. Acad. Sci. USA 82: 8545-8547.

Jaisson, P. 1971. Expériences sur l'agressivité chez les fourmis. C. R. Acad. Sci. Paris Ser. D 273: 2320 2323.

1985. Social behavior, pp. 673-694. In G. A. Kerkut $\&$ L. I. Gilbert [eds.], Comprehensive insect physi- ology, biochemistry and pharmacology, vol. 9. Pergamon, Oxford.

Kloft, W. J. 1983. Interspecific trophallactic relations between ants of different species, genera and subfamilies-an important strategy in population ecology. Ann. Entomol. 1: 85-86.

Koeniger, N. 1984. Brood care and recognition of pupae in the honeybee (Apis mellifera) and the hornet (Vespa crabro), pp. 267-283. In T. Lewis [ed.], Insect communication. Academic, London.

LaMon, B. \& H. Topoff. 1985. Social facilitation of eclosion in the fire ant, Solenopsis invicta. Dev. Psychobiol. 18: 367-374

Le Masne, G. 1953. Observations sur les relations entre le couvain et les adultes chez les fourmis. Ann. Sci. Nat. 15: 1-56.

Lenoir, A. 1981. Brood retrieving in the ant Lasius niger. Sociobiology 6: 153-178.

1984. Brood-colony recognition in Cataglyphis cursor worker ants (Hymenoptera: Formicidae). Anim. Behav. 32: 942-944.

Maschwitz, U., K. Dumpert \& K. R. Tuck. 1986. Ants feeding on anal exudate from tortricid larvae: a new type of trophobiosis. J. Nat. Hist. 20: 1041-1050.

Masuko, K. 1986. Larval hemolymph feeding: a nondestructive parental cannibalism in the primitive ant Amblyopone silvestrii Wheeler (Hymenoptera: Formicidae). Behav. Ecol. Sociobiol. 19: 249-255.

Menzel, R. 1985. Learning in honey bees in an ecological and behavioral context, pp. 55-74. In $\mathrm{B}$. Holldobler \& M. Lindauer [eds.], Experimental behavioral ecology and sociobiology. Gustav Fischer, Stuttgart.

Nordlund, D. A. \& W. J. Lewis. 1976. Terminology of chemical releasing stimuli in intraspecific and interspecific interactions. J. Chem. Ecol. 2: 211-220.

Petralia, R. S. \& S. B. Vinson. 1979. Developmental morphology of larvae and eggs of the imported fire ant, Solenopsis invicta. Ann. Entomol. Soc. Am. 72: $472-484$.

Robinson, S. W. \& J. M. Cherrett. 1974. Laboratory investigations to evaluate the possible use of brood pheromones of the leaf-cutting ant Atta cephalotes (L.) (Formicidae, Attini) as a component in an attractive bait. Bull. Entomol. Res. 63: 519-529.

Roelofs, W. L. 1981. Attractive and aggregating pheromones, pp. 215-235. In D. A. Nordlund, R. L. Jones $\&$ W. L. Lewis [eds.], Semiochemicals: their role in pest control. Wiley, New York.

Tschinkel, W. R. In press. Social control of egg-laying rate in queens of the fire ant, Solenopsis invicta. Physiol. Entomol.

Vander Meer, R. K. 1983. Semiochemicals and the red imported fire ant (Solenopsis invicta) (Hymenoptera: Formicidae). Fla. Entomol. 66: 139-161.

1986. The trail pheromone complex of Solenopsis invicta and Solenopsis richteri, pp. 201-210. In C. S. Lofgren \& R. K. Vander Meer [eds.], Fire ants and leaf cutting ants: biology and management. Westview, Boulder, Colo.

1988. Behavioral and biochemical variation in the fire ant, Solenopsis invicta. In R. L. Jeanne [ed.], Interindividual behavioral variability in social insects. Westview, Boulder, Colo.

Vander Meer, R. K. \& L. Morel. 1988. Brood pheromones in ants. In J. C. Trager [ed.], Advances in myrmecology. Brill, New York.

Vander Meer, R. K. \& D. P. Wojcik. 1982. Chemical mimicry in the myrmecophilous beetle Myrmecaphodious excavaticollis. Science 218: 806-808. 
Vander Meer, R. K., D. F. Williams \& C. S. Lofgren. 1981. Hydrocarbon components of the trail pheromone of the red imported fire ant, Solenopsis invicta. Tetrahedron Lett. 22: 165l-1654.

Vander Meer, R. K., F. Alvarez \& C. S. Lofgren. 1988. Isolation of the trail recruitment pheromone of Solenopsis invicta. J. Chem. Ecol. 14: 825-838.

Walsh, J. P. \& W. R. Tsehinkel. 1974. Brood recognition by contact pheromone in the red imported fire ant, Solenopsis invicta. Anim. Behav. 22: 695704.

Watkins, J. F. \& T. W. Cole. 1966. The attraction of army ant workers to secretions of queens. Tex. J. Sci 18: 254-265.
Way, M. J. 1963. Mutualism between ants and honeydew-producing Homoptera. Annu. Rev. Entomol. 8: 307-344.

Wilson, E. O. 1962. Chemical communication among workers of the fire ant Solenopsis saevissima ( $\mathrm{Fr}$. Smith). 1. The organization of mass-foraging. 2. An information analysis of the odour trail. 3 . The experimental induction of social responses. Anim. Behav. 10: 134-164.

1971. The insect societies. Harvard University, Cambridge, Mass.

Received for publication 21 September 1987; accepted 22 April 1988. 